\title{
Pemanfaatan Big Data pada Instansi Pelayanan Publik
}

\author{
Ariraya Sulistya Sedayu ${ }^{1}$, Andriyansah ${ }^{2}$ \\ ${ }^{1}$ Program Doktor Ilmu Manajemen, Fakultas Ekonomi Universitas Terbuka dan Fungsional Perencana \\ Muda Kementerian Energi dan Sumber Daya Mineral \\ 2 Fakultas Ekonomi, Universitas Terbuka \\ E-mail:530057018@ecampus.ut.ac.id,andri@ecampus.ut.ac.id
}

\begin{tabular}{|c|c|}
\hline Article Info & Abstract \\
\hline $\begin{array}{l}\text { Article History } \\
\text { Received: } 2021-09-20 \\
\text { Revised: 2021-09-28 } \\
\text { Published: 2021-11-02 }\end{array}$ & $\begin{array}{l}\text { The advent of the internet has revolutionized the way the world works so fast. The } \\
\text { world is now entering the era of digitalization, an era that has become a pattern for the } \\
\text { digital economy and big data. Big Data involves the processes of data creation, storage, } \\
\text { information mining, and data analysis that stand out in terms of volume, velocity, and } \\
\text { variation. For industry or practitioners, big data has opened up opportunities to set } \\
\text { business strategies. This study wants to see the extent to which Big Data technology } \\
\text { has been used in Indonesian Public Service Agencies. The research method uses } \\
\text { literature study with a traditional-conceptual approach. Primary data are journals that } \\
\text { are already related to the topic the author is studying and some news sourced from } \\
\text { social media. In conclusion, the use of Big Data in Indonesia has begun to develop in the } \\
\text { public sector. The results of the literature review from this research are a conceptual } \\
\text { framework that will be developed for further research. }\end{array}$ \\
\hline Artikel Info & Abstrak \\
\hline $\begin{array}{l}\text { Sejarah Artikel } \\
\text { Diterima: } 2021-09-20 \\
\text { Direvisi: 2021-09-28 } \\
\text { Dipublikasi: } 2021-11-02\end{array}$ & $\begin{array}{l}\text { Munculnya internet telah merevolusi cara dunia bekerja begitu cepat. Dunia kini } \\
\text { memasuki era digitalisasi, era yang menjadi pola ekonomi digital dan big data. Big Data } \\
\text { melibatkan proses pembuatan data, penyimpanan, penggalian informasi, dan analisis } \\
\text { data yang menonjol dalam hal volume, velocity, dan variasi. Bagi industri atau praktisi, } \\
\text { big data telah membuka peluang untuk menetapkan strategi bisnis. Penelitian ini ingin } \\
\text { melihat sejauh mana teknologi Big Data telah digunakan di Instansi Pelayanan Publik } \\
\text { Indonesia. Metode penelitian menggunakan studi pustaka dengan pendekatan } \\
\text { tradisional-konseptual. Data primer adalah jurnal yang sudah berhubungan dengan } \\
\text { topik yang penulis pelajari dan beberapa berita yang bersumber dari media sosial. } \\
\text { Kesimpulan penggunaan Big Data di Indonesia sudah mulai berkembang di sektor } \\
\text { publik. Hasil kajian pustaka dari penelitian ini merupakan kerangka konseptual yang } \\
\text { akan dikembangkan untuk penelitian selanjutnya. }\end{array}$ \\
\hline
\end{tabular}

\section{PENDAHULUAN}

Laporan terbaru dari agensi pemasaran We Are Social dan platform manajemen media sosial Hootsuite mengungkapkan bahwa lebih dari populasi di Indonesia sebagian masyaraka aktif menggunakan media social, pada Januari 2021. Dalam laporan Digital 2021 uyang berjudul The Latest Insights Into The State of Digital, disebutkan bahwa dari total 274,9 juta orang di Indonesia, 170 juta di antaranya telah menggunakan media sosial. Dengan demikian, tingkat Persentasenya sekitar 61,8\%. Pengguna aktif media sosial di Indonesia tumbuh 10 juta atau sekitar 6,3\% dibandingkan Januari 2020. Pada periode yang sama, pengguna internet di Indonesia tumbuh 27 juta atau 15,5\% menjadi 202,6 juta, porsentasinya dapat dilihat pada berikut ini:

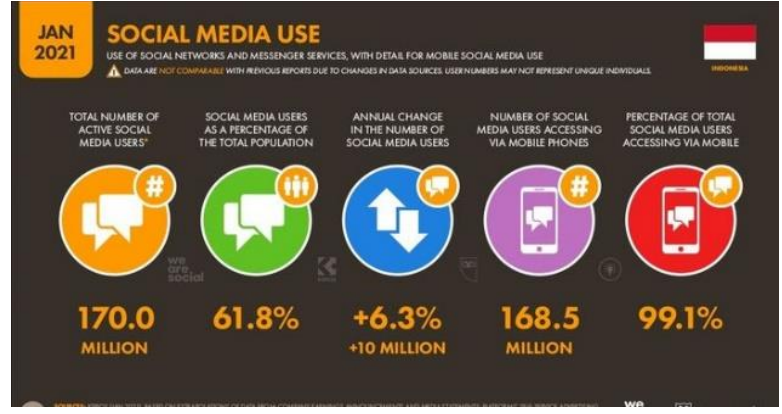

Gambar 1. Persentase media sosial di Indonesia (We Are Social)

Generasi milenial yang biasa dikenal dengan generasi $\mathrm{Y}$ dan generasi $\mathrm{Z}$ mendominasi penggunaan media sosial di Indonesia yang sebagian besar adalah anak muda dengan rentang usia 25-34 tahun. Hampir semua (99,1 $\%, 168,5$ juta) pengguna media sosial mengakses 
melalui perangkat mobile seperti smartphone. Selain itu, sebagaimana dihimpun KompasTekno dari laporan We Are Social dan Hootsuite, Rabu 24 Februari 2021, rata-rata masyarakat Indonesia menggunakan media sosial setiap tiga jam 14 menit sehari. Dilihat dari frekuensi pemakaian bulanannya, urutan pertama aplikasi media sosial yang paling banyak digunakan di Indonesia justru ditempati oleh YouTube, dibahas WhatsApp, Instagram, Facebook, kemudian Twitter secara berurutan. Media yang sering dilihat oleh pengguna di Indonesia, dapat dilihat pada gambar berikut ini:

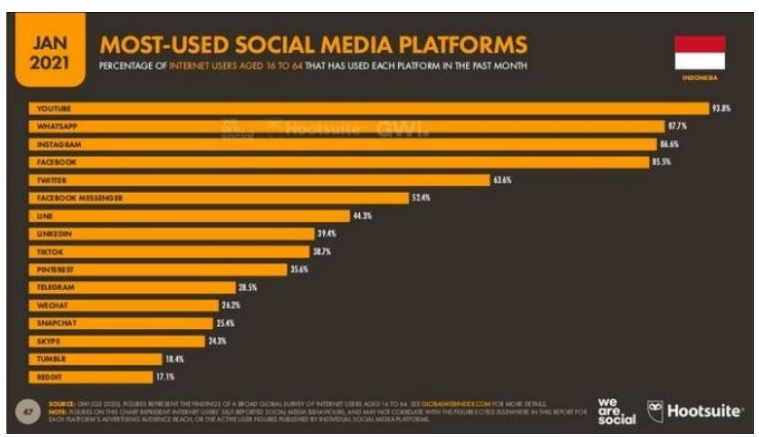

Gambar 2. Media sosial yang paling sering digunakan di Indonesia (We Are Social)

Namun, jika dilihat dari total durasi penggunaan masing-masing media social pada gambar 2, jaringan dari Facebook menempati posisi tiga besar. Mereka adalah WhatsApp di mana pengguna media sosial Indonesia menghabiskan rata-rata 30,8 jam per bulan, kemudian Facebook dengan 17 jam per bulan, dan Instagram dengan 17 jam per bulan. TikTok mengikuti di urutan keempat dengan waktu penggunaan rata-rata 13,8 jam per bulan, kemudian Twitter di urutan kelima dengan 8,1 jam per bulan. Data menarik lainnya yang juga terungkap adalah rata-rata orang Indonesia ternyata memiliki 10 akun media sosial per orang. Selain itu, $60 \%$ pengguna media sosial menggunakannya untuk pekerjaan seperti membangun relasi dan menjalankan bisnis. Saat ini, Facebook merupakan sumber informasi yang berharga bagi lembaga komersial dan nonkomersial, penelitian, dan pemerintah untuk mempelajari pola sosial (interaksi, hubungan, dan mobilitas sosial).

Data informasi seperti demografi, perilaku berbagi dan pemberian tag seperti pada fanpage tertentu, adalah sebagian kecil dari jutaan informasi berharga lainnya yang dihasilkan Facebook. Tak jarang, data yang dihasilkan Facebook dijadikan dasar kebijakan atau strategi institusi yang berkepentingan. Kita sedang memasuki tren yang disebut Big Data, era dimana ketersediaan data sosial yang terekam secara digital semakin melimpah. Bagi industri atau praktisi, big data telah membuka peluang untuk menetapkan strategi dan inovasi dalam mengolah, menganalisis, dan menyimpan data dengan volume tinggi dan tingkat volatilitas tinggi secara cepat dan efektif. Bagi akademisi, Big Data telah mendobrak tradisi lama penelitian ilmu sosial. Big data memberikan solusi bagi penelitian sosial konvensional, terutama untuk menangkap realitas seperti pola jaringan komunikasi, penyebaran informasi, atau bahkan memprediksi pola gerakan sosial atau politik berdasarkan perilaku online. Istilah-istilah seperti webometrics, analisis jaringan sosial, penelitian sosial digital, ilmu sosial web atau ilmu sosial komputasi menandakan transisi dari penelitian sosial konvensional ke penelitian sosial dunia maya atau e-research, yang mana unit analisis transisi dari manusia ke algoritma (Lupton , 2015:17). Banyak pengembang aplikasi memanfaatkan big data. Hastags.org, misalnya, mampu menampilkan grafik topik Twitter yang diambil dari Application Program Interface (API) streaming Twitter dalam jangka waktu tertentu. Wolframalpha, aplikasi berbasis web yang menghasilkan laporan dalam bentuk cluster atau pemetaan jaringan teman dari level satu atau level dua ke tempat-tempat yang pernah Anda kunjungi (check-in di Facebook).

Kelimpahan data secara kuantitas dan ragamnya memerlukan mekanisme analisis data yang komprehensif, atau paling tidak mewakili populasi data yang besar. Meskipun ada banyak aplikasi untuk menganalisis big data yang tersedia di internet, akses ke big data itu sendiri sangat terbatas. Facebook, misalnya, mengubah kebijakan akses API pada pertengahan 2015. Hal ini dilakukan untuk melindungi data pengguna Facebook dari pengembang aplikasi yang meraup keuntungan ekonomi (Techcrunch, 2015). Penelitian yang menggunakan big data masih belum populer di Indonesia, khususnya bagi para peneliti sosial. Keterbatasan software yang masih ada di produksi luar negeri dan terbatasnya akses publikasi ilmiah big data menjadi salah satu penyebabnya.

Ada beberapa peneltian yang serupa diantarnya ialah (Agustini, K., 2017). Meneliti tentang inovasi teknologi dalam pendidikan melalui big data analytic dan personalized learning. Berikut dilakukan oleh (Narendra, A. P., 2015) meneliti tentang data besar, data analisis, 
dan pengembangan kompetensi pustakawan. Selanjutnya dilakukan oleh (Nafah, H. K., \& Purnaningrum, E., 2021) meneliti tentang penggunaan big data melalui analisis google trends untuk mengetahui perspektif pariwisata indonesia di mata dunia. Terakhir oleh (Pratama, E. E., \& Sastypratiwi, H., 2021) menganalisis kecenderungan informasi terkait covid-19 berdasarkan big data sosial media dengan menggunakan metode data mining.

\section{METODE PENELITIAN}

Literatur Artikel ini membahas hal-hal teknis terkait teknologi pendukung big data, namun memberikan gambaran tentang penerapan big data pada instansi pelayanan public Indonesia melalui review jurnal yang telah dilakukan dari sumber terpercaya. Penelitian ini merupakan studi literatur dengan pendekatan konseptual tradisional. Tinjauan Pustaka adalah produk tertulis yang mengeksplorasi topik atau hasil penelitian yang telah dicapai, tanpa deskripsi metodologi ilmiah (Jesson et al., 2011:10). Ada dua pendekatan dalam penelitian literatur yaitu pendekatan tradisional dan pendekatan sistematis. Pendekatan tradisional dalam literature review memiliki beberapa pendekatan seperti critical approach, konseptual review, current review, expert review, scoping review. Artikel ini menggunakan pendekatan tradisional untuk mensintesis pengetahuan atau hasil penelitian tentang topik tertentu, yang dalam hal ini adalah Big Data, dengan tujuan untuk memberikan pemahaman yang mendalam tentang topik tersebut. Data primer dalam literature review ini adalah jurnal-jurnal yang membahas tentang peluang dan tantangan penerapan big data, yang dipilih secara subyektif oleh peneliti. Pemilihan jurnal tidak hanya berdasarkan topik, tetapi juga publikasi dan kutipan jurnal tersebut. Penulis menyusun kembali ide-ide penting dari jurnal terpilih secara logis, sistematis, dan argumentatif kritis.

\section{HASIL DAN PEMBAHASAN}

\section{A. Konseptual Big Data}

Big Data adalah teknologi, teknik, atau inisiatif yang berdiri sendiri. Big Data adalah tren yang mencakup bidang bisnis dan teknologi yang luas. Big Data mengacu pada teknologi dan inisiatif yang melibatkan data yang sangat beragam, berubah dengan cepat, atau sangat besar sehingga terlalu sulit untuk ditangani secara efektif oleh teknologi, keahlian, atau infrastruktur konvensional efektif. Dengan kata lain, Big Data memiliki ukuran (volume), kecepatan (velocity), atau keragaman (variety) yang terlalu ekstrim untuk dikelola dengan teknik konvensional. Big Data melibatkan proses pembuatan data, penyimpanan, pencarian informasi, dan analisis yang menonjol dalam hal volume, kecepatan, dan beragam. (Kompasiana: Januari, 2016). Menurut (Eaton, Dirk, Tom, George, \& Paul) Big Data adalah istilah yang berlaku untuk informasi yang tidak dapat disajikan atau dianalisis menggunakan alat tradisional. Menurut (Dumbille, 2012), Big Data adalah data yang melebihi kapasitas pemrosesan database sistem konvensional yang ada. Data terlalu besar dan terlalu cepat atau tidak sesuai dengan database struktur arsitektur yang ada. Untuk mendapatkan nilai dari data tersebut, maka harus memilih cara alternatif untuk mengolahnya. Big data adalah aset informasi bervolume tinggi, berkecepatan tinggi, dan/atau sangat beragam yang menuntut efisiensi biaya, bentuk pemrosesan informasi inovatif yang memungkinkan peningkatan wawasan, pengambilan keputusan, dan proses otomatisasi.

Secara garis besar, big data tersebar di ruang elektronik (salah satunya: internet) yang berasal dari berbagai sumber yang kompleks dimana prosesnya dilakukan secara bertahap (collection, organization, storage hingga analysis) dan membutuhkan resource yang tidak murah. Karena skalanya yang begitu besar dan prosedur yang kompleks, maka big data dibagi menjadi lima kategori, yaitu: 1) sumber data; 2) format isi; 3) penyimpanan data; 4) pementasan data; 5) pengolahan data. Media sosial dikategorikan sebagai big data karena merupakan sumber data atau informasi yang dapat dibagikan atau dipertukarkan antar individu atau kelompok (komunitas) melalui URL. Data spesifik media sosial, (Batrinca dan Treleaven 2015) mengklasifikasikannya menjadi dua jenis: kumpulan data historis (data yang sebelumnya telah dikumpulkan dan disimpan) dan data waktu nyata (data diambil secara langsung tanpa jeda waktu tertentu, misalnya e.g. live feeds).

Menurut (Alamsyah. 2015), tools yang tersedia untuk aplikasi big data dapat dikategorikan menjadi 2, yaitu: berbayar (personalized software) dan tidak berbayar (berbasis open source software). Alat tersebut berkaitan dengan 4 (empat) tahapan kegiatan 
dan dukungan teknologi pada Big Data yang meliputi (Alamsyah, 2015):

1) Acquired, berkaitan dengan sumber dan cara memperoleh data.

2) Accessible, terkait dengan daya akses data. Data yang telah dikumpulkan memerlukan tata kelola, integrasi, penyimpanan, dan komputasi agar dapat dikelola.

3) Analytic, berkaitan dengan informasi yang akan diperoleh, atau hasil pengelolaan data yang disajikan. Analisis tersebut dapat berupa deskriptif (penggambaran data), diagnostik (mencari penyebab berdasarkan data), prediktif (memprediksi kejadian yang akan datang) atau preskriptif analytics (pilihan pilihan dan pilihan setiap opsi).

4) Application, terkait visualisasi dan pelaporan hasil dari analytics.

Untuk software berbayar (proprietary software) yang mendukung big data analytics, ini merupakan model baru bagi beberapa vendor/perusahaan dengan menawarkan Big Data untuk mendukung pertumbuhan di industri lain. Seperti pada perusahaan telekomunikasi yang menyediakan layanan data analytics untuk beberapa instansi/lembaga pemerintah pusat dan daerah, industri penerbangan, dan kesehatan.

\section{B. Pelayanan Publik}

Undang-undang Nomor 25 Tahun 2009 tentang Pelayanan Publik mendefinisikan pelayanan publik sebagai suatu kegiatan atau rangkaian kegiatan dalam memenuhi kebutuhan pelayanan sesuai dengan peraturan perundang-undangan bagi setiap warga negara dan penduduk atas barang, jasa, dan/atau pelayanan administrasi yang disediakan oleh penyelenggara pelayanan publik. Seiring dengan perkembangan manajemen pemerintahan dan dalam upaya mewujudkan pelayanan prima dan berkualitas, paradigma pelayanan publik berkembang dengan fokus pada pengelolaan barang dan jasa yang berorientasi pada kepuasan pelanggan. Pelayanan publik ini mengatur pengadaan dan penyerahan barang publik yang dilakukan oleh pemerintah yang dananya sebagian atau seluruhnya bersumber dari Anggaran Pendapatan dan Belanja Negara, dan/atau Anggaran Pendapatan dan Belanja Daerah yang dilakukan oleh badan usaha yang modal pendiriannya sebagian. atau berasal dari kekayaan negara, dan/atau kekayaan daerah yang dipisahkan dan pembiayaannya tidak berasal dari Anggaran Pendapatan dan Belanja Negara. Secara teoritis, tujuan pelayanan publik pada dasarnya adalah memuaskan masyarakat. Untuk mencapai kepuasan itu kualitas pelayanan prima terlihat dari:

1) Transparansi yaitu pelayanan yang terbuka, mudah dan dapat diakses oleh semua pihak yang membutuhkannya dan disediakan cukup dan mudah dipahami;

2) akuntabilitas, yaitu pelayanan yang dapat dipertanggungjawabkan sesuai dengan ketentuan peraturan perundangundangan;

3) conditional, yaitu pelayanan yang sesuai dengan ketentuan dan kemampuan penyedia dan penerima layanan untuk berpegang teguh pada prinsip efisiensi dan efektivitas;

4) partisipatif, yaitu pelayanan yang dapat mendorong peran dan masyarakat dalam penyelenggaraan pelayanan public dengan memperhatikan aspirasi, kebutuhan, dan harapan publik;

5) Persamaan hak, yaitu pelayanan yang tidak dilakukan diskriminasi dilihat dari segala aspek, terutama suku, ras, agama, golongan, status sosial, dan lain-lain;

6) keseimbangan hak dan kewajiban, yaitu jasa yang mempertimbangkan aspek keadilan antara pemberi dan penerima pelayanan publik (Sinambela, dkk, 2010: 6).

(Fitzsimmons dalam Rusli, 2004) berpendapat ada 5 (lima) indikator pelayanan publik yaitu reliability/keandalan yang tinggi ditandai dengan pemberian pelayanan yang tepat dan benar; tangible ditandai dengan penyediaan sumber daya yang cukup sumber daya manusia dan lainnya; responsiveness, ditandai dengan keinginan untuk melayani konsumen dengan cepat; assurance, memperhatikan etika dan moral dalam memberikan pelayanan, dan empati yang ditandai dengan tingkat kemauan untuk mengetahui keinginan dan kebutuhan konsumen.

\section{Pemanfaatan Big Data dalam Pelayanan Publik}

Data dan bisnis seolah menjadi satu paket yang lengkap, keduanya tidak bisa dipisahkan. Sebagai bisnis yang sedang berjalan di era 
teknologi tentunya data yang lengkap dengan analisa menjadi bagian terpenting yang dapat mendukungnya arah kebijakan dalam menjalankan bisnis. Analisis data yang lengkap bukan lagi sekedar kompetensi penting bagi organisasi perusahaan tetapi sebagai kontrol pasar dan berfungsi sebagai dasar untuk.

\section{Acuan dimana bisnis akan berjalan dan berkembang.}

Selain berguna untuk analisis bisnis, teknologi Big Data juga dapat digunakan secara luas di pemerintah. Beberapa peluang penggunaan Big Data di sektor publik antara lain: umpan balik dan tanggapan publik dari sistem informasi layanan pemerintah dan dari media sosial, sebagai dasar perumusan kebijakan dan peningkatan pelayanan publik; menemukan solusi untuk masalah data yang ada berdasarkan data yang tersedia, misalnya dengan menganalisis informasi cuaca dan tingkat kesuburan tanah, pemerintah dapat menetapkan atau merekomendasikan jenisjenis varietas tanaman yang ditanam oleh wilayah dan waktu tertentu.

Di bidang Pertambangan, teknologi Big Data juga dapat mengidentifikasi sumber daya mineral dan energi baru. Teknologi Big Data tidak hanya memungkinkan tata kelola yang baik, tetapi juga memungkinkan pemerintah menjawab permasalahan kabupaten dengan cepat dan tepat - mulai dari banjir, panen, hingga kemiskinan. Sebagai contoh Kabupaten Bojonegoro merupakan salah satu kabupaten di Jawa Timur memasuki tahap Big Data dalam program Open Government Partnership, pemerintahan terbuka di sini tidak lain adalah adalah pemerintahan yang transparan, membuka akses informasi seluasluasnya kepada rakyat, membuka ruang keterlibatan warga negara untuk mengatur pemerintahan. Bojonegoro terpilih sebagai satu-satunya perwakilan Indonesia dalam Proyek Percontohan Pemerintah Terbuka, ini adalah gerakan pemerintahan yang mendorong dan memberdayakan pemerintahan inovatif yang terbuka, partisipatif, dan responsif. Dalam program ini, Bojonegoro berarti setara dengan kota-kota lain di dunia, seperti Seoul, Paris, Madrid, Buenos Aires dan Sao Paulo.

Mengacu pada besarnya manfaat yang dapat ditawarkan oleh tren teknologi big data, dan apa saja tantangannya yang muncul dalam penerapannya. Penerapan teknologi big data dalam suatu organisasi atau perusahaan dapat dilihat dari fungsi-fungsi yang sudah tersedia pada infrastruktur IT, sehingga dapat berjalan pekerjaan yang terkait dengan aplikasi mobil, sosial, dan big data analytics. Semoga hasil kajiannya bisa memberikan informasi dan inspirasi agar implementasi teknologi big data di Indonesia dapat semakin bermanfaat.

\section{SIMPULAN}

Big Data adalah tren yang mencakup area yang luas di dunia bisnis dan teknologi. Big Data mengacu pada teknologi dan inisiatif yang melibatkan data yang sangat beragam, berubah dengan cepat, atau sangat besar sehingga terlalu sulit untuk ditangani secara efektif oleh teknologi, keahlian, atau infrastruktur konvensional. Big data analytics (BDA) memberikan nilai bisnis kepada perusahaan dengan berbagai cara dan banyak ahli yang mulai memahami pentingnya keunggulan kompetitif, dalam hal ini terkait dengan bagaimana memahami rantai nilai dari big data analytics. Peluang dan manfaat penerapan big data sangat potensial baik dalam organisasi bisnis maupun organisasi publik. Dengan menggunakan data, strategi bisnis dan kebijakan publik dapat dirancang dan diimplementasikan secara lebih efektif dan tepat untuk mencapai target. Manfaat teknologi Big Data sudah banyak dirasakan di berbagai sektor. Perusahaan yang bergerak di bidang bisnis dapat memanfaatkan informasi berharga dari Big Data untuk mengoptimalkan proses pengambilan keputusan, sehingga target memaksimalkan keuntungan dapat tercapai. Sementara itu, institusi yang bergerak di bidang pelayanan publik dapat memanfaatkan output informasi dari Big Data untuk memaksimalkan tingkat kepuasan pelayanan kepada masyarakat.

Implikasi dari temuan ini adalah sekolah, guru dan ekosiistem sekolah tidak mampu memberi pengaruh positif terhadap ahklak siswa. Sekolah, guru dan ekosistem sekolah harus berbesar hati dan bersedia untuk memperbaiki segala proses dan metode pembelajaran terutama di era pembelajaran dalam jejaring (daring). Hal tersebut perlu dilakukan karena pemeblajaran dalam jejaring (daring) tetap akan dilaksanakan dimasa yang akan datang, walaupun tidak ada kejadian luar biasa seperti pandemic, Kontribusi dan rekomendasi penelitian masa depan, penelitian seharusnya dilakukan pada situasi normal atau multi keadaan. Dengan demikian 
diharapkan responden (siswa) juga akan memberi respon secara normal sesuai keadaan yang sering terjadi dan dialami.

\section{DAFTAR RUJUKAN}

Abbasi, A., Sarker, S., Chiang, R.H.L., 2016. Big data research in information systems: toward an inclusive research agenda. J. Assoc. Inf. Syst. 17, 1-32

Agustini, K. (2017, September). Inovasi Teknologi dalam Pendidikan melalui Big Data Analytic dan Personalized Learning. In Seminar Nasional Pendidikan Teknik Informatika (SENAPATI) (No. 7).

Ashari, Mochamad, 2015. Big Data Industry and Academic Point of View. Konferensi Big Data Indonesia.

Chrisvania, N. (2017). Social media and technology's impact on business, society, and culture. $\quad$ https://socialmediaweek.org/ jakarta/2017/01/06/strategi-dalamimplementasi-big-data/.

Gunasekaran, A., Papadopolus, T., Dubey, R., Wamba, S. F., Childe, S. J., Hazen, B., \& Akter, S. (2017). Big Data Analytic and Supply Chainand Organizational Performance. Journal of Bussines Research, 70

Kusumasari,Dita, Rafizan, Onni. (2017). Studi Implementasi Sistem Big Data Untuk Mendukung Kebijakan Komunikasi Dan Informatika. Jurnal Masyarakat Telematika dan Informasi. ISSN 2621-1386 Volume:8 No. 2.
Nafah, H. K., \& Purnaningrum, E. (2021). Penggunaan Big Data Melalui Analisis Google Trends Untuk Mengetahui Perspektif Pariwisata Indonesia di Mata Dunia. SNHRP, 3, 430-436.

Narendra, A. P. (2015). Data besar, data analisis, dan pengembangan kompetensi pustakawan. Record and Library Journal, 1(2), 83-93.

Pratama, E. E., \& Sastypratiwi, H. (2021). Analisis Kecenderungan Informasi Terkait Covid-10 Berdasarkan Big Data Sosial Media dengan Menggunakan Metode Data Mining. Jurnal Informatika Polinema, 7(2), 1-6.

Sirait, Emyana Ruth Eritha, 2016, "Implementasi Teknologi Big Data di Lembaga Pemerintahan Indonesia", Jurnal Penelitian Pos dan Informatika, Vol. 6.

Stephanie, C. Riset Ungkap Lebih dari Separuh Penduduk Indonesia "Melek" Media Sosial https://tekno.kompas.com/read/2021/02/ 24/08050027/riset-ungkap-lebih-dariseparuh-penduduk-indonesia-melek-mediasosial

Vience Mutiara Rumata, " Peluang dan Tantangan Big Data dalam Penelitian Ilmu Sosial: sebuah Kajian Literatur", Jurnal Penelitian Komunikasi dan Opini Publik, Vol 20, No 1. Agustus 2016. 